\title{
A syndrome of epilepsy, dementia, and amelogenesis imperfecta: genetic and clinical features
}

\author{
JOHN CHRISTODOULOU*, ROGER K HALL + , SAMUEL MENAHEM , \\ IAN J HOPKINS $\$$, AND JOHN G ROGERS* \\ From the Departments of Genetics*, Dentistry†, Medicine $\ddagger$, and Neurology§, Royal Children's Hospital, \\ Parkville, Victoria 3052, Australia.
}

SUMmaRY A family is described with six members affected by a syndrome of epilepsy, dementia, and amelogenesis imperfecta (Kohlschütter's syndrome). An autosomal recessive pattern of inheritance is established for this disorder.

Kohlschütter's syndrome ${ }^{1}$ (McKusick No 22675) is an inherited disorder characterised by progressive dementia preceded by spasticity and epilepsy. It is associated with a symmetrical, generalised developmental defect of tooth enamel known as amelogenesis imperfecta affecting both primary and permanent dentition, which causes the teeth to have thin, yellow, or rough crowns. It has been unclear whether this disorder was inherited in an X linked recessive or autosomal recessive manner. We report

Received for publication 27 November 1987.

Revised version accepted for publication 1 April 1988. here a family which clearly shows an autosomal recessive pattern of inheritance.

\section{Case reports}

The pedigree of this family is shown in fig 1 . There are six affected subjects. The first child remains normal and the seventh child is almost certainly affected. The parents of these patients are Sicilian in origin and, although they come from the same small, close knit town (population approximately 5000), they deny consanguinity. Four maternal relatives (all female) are said to be mentally retarded, but the

Mental retardation, cause unknown

Neurological degeneration associated with enamel maldevelopment

I
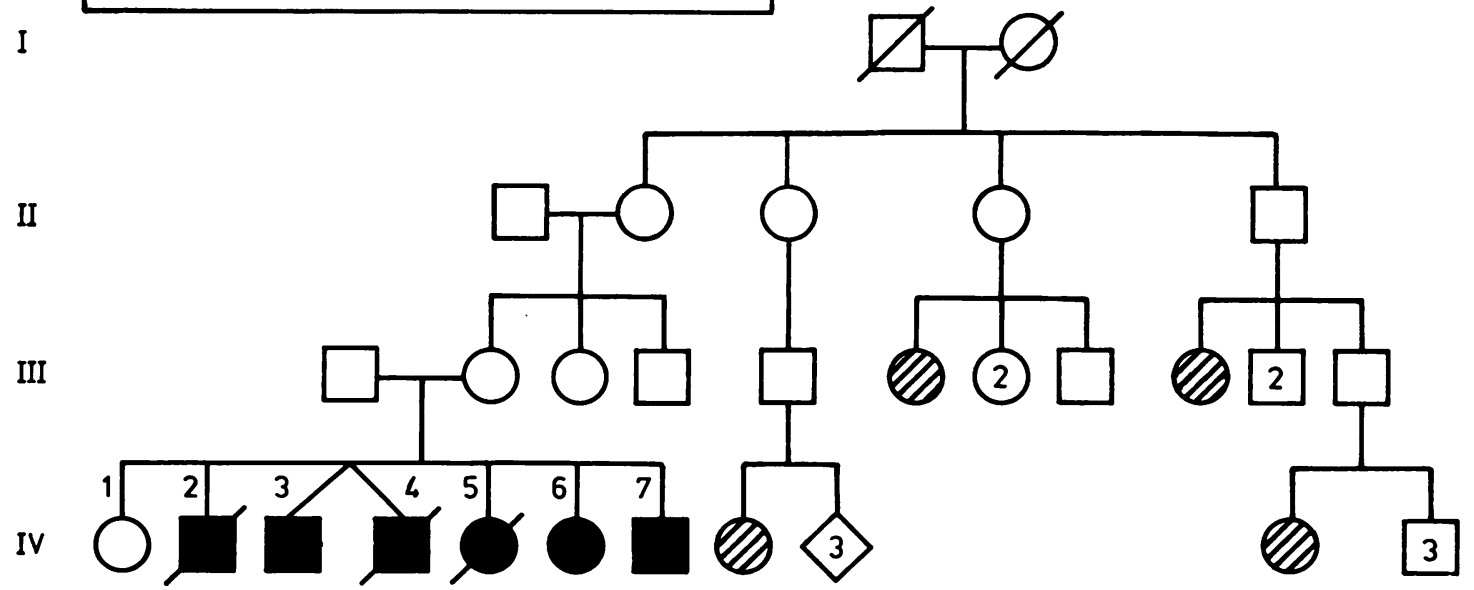

FIG 1 Pedigree of the reported kindred. 
state of their dentition is not known. The paternal lineage shows no dental, neurological, or other relevant features.

IV. 1 is a female of normal development and intellect who has no dental abnormalities. She is now 15 years old.

IV. 2 was born at term of a normal pregnancy and an uncomplicated delivery. He developed normally until the age of 11 months when he presented to hospital in status epilepticus. These fits proved extremely difficult to control despite treatment with various anticonvulsants, including phenytoin, primidone, and nitrazepam. His development slowed and subsequently regressed, and he is now severely intellectually handicapped. At the age of seven years he had no speech and was unable to feed himself, although he could walk with support and sit unaided.

With eruption of his primary dentition at six months of age, abnormality of the enamel was noted but its significance was not appreciated. He died at the age of $101 / 2$ years from pneumonia, epilepsy, and emaciation.
This first affected child had extensive investigations, including a full blood examination, serum sodium, potassium, chloride, calcium, magnesium, blood glucose, chest $x$ ray, and skull $x$ ray which were all normal. An electroencephalogram showed generalised excessive slow wave activity but no focal abnormalities. CSF examination showed no abnormalities at the time of initial presentation but was found to have a raised lactate level of $6.75 \mathrm{mmol} / \mathrm{l}$ (normal range 1.04 to 2.26 ) during the illness leading to his death. At that time, CSF amino acid analysis showed a glycine level of $18.2 \mu \mathrm{mol} / \mathrm{l}$ (normal range 3.0 to 10.2 ) and an alanine level of $57 \cdot 2 \mu \mathrm{mol} / 1$ (normal range 4.4 to 42.0 ), with all other amino acid concentrations being normal. Multiple urine amino and organic acid screens failed to detect any abnormalities. Acid base and liver function tests were also normal. Plasma C26:22 and C24:22 long chain fatty acid levels were normal, as were white blood cell lysosomal enzyme activities (including $\beta$-galactosidase, hexosaminidase $A$ and $B$, arylsulphatase $A$, acid phosphatase, $\beta$-glucuronidase, $\alpha$-mannosidase, $\alpha$-fucosidase, $\beta$-glucocerebrosidase,

TABLE Clinical details of the affected family members.

\begin{tabular}{|c|c|c|c|c|c|}
\hline Pedigree No & Sex & $\begin{array}{l}\text { Age of onset } \\
\text { of seizures }(\mathrm{mth})\end{array}$ & $\begin{array}{l}\text { Amelogenesis } \\
\text { imperfecta }\end{array}$ & $\begin{array}{l}\text { Neuromotor } \\
\text { development }\end{array}$ & Present age (y) \\
\hline IV. 2 & $\mathbf{M}$ & 11 & Yes & Regression & $10 \cdot 5^{*}$ \\
\hline IV. 3 & $\mathbf{M}$ & 18 & Yes & Regression & 12 \\
\hline IV.4 & M & 13 & Yes & Regression & $10^{*}$ \\
\hline IV.5 & $\mathrm{F}$ & 11 & Yes & Delayed & $1 \cdot 5^{*}$ \\
\hline IV.6 & $\mathrm{F}$ & 22 & Yes & Delayed & 6 \\
\hline IV.7 & $\mathbf{M}$ & 7 & Yes & Delayed & $1 \cdot 5$ \\
\hline
\end{tabular}

${ }^{*}$ Died at the age indicated.

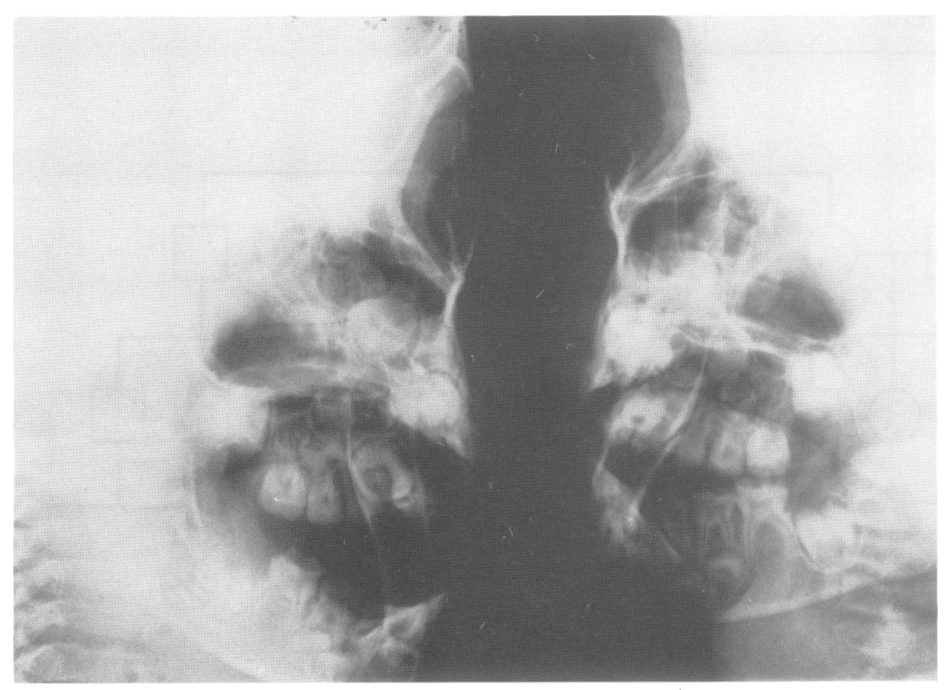

FIG 2 Dental radiographs of IV.6 taken at four years of age. Note the thin, hypoplastic enamel of the primary dentition molars and cuspids and developing first permanent molars. 


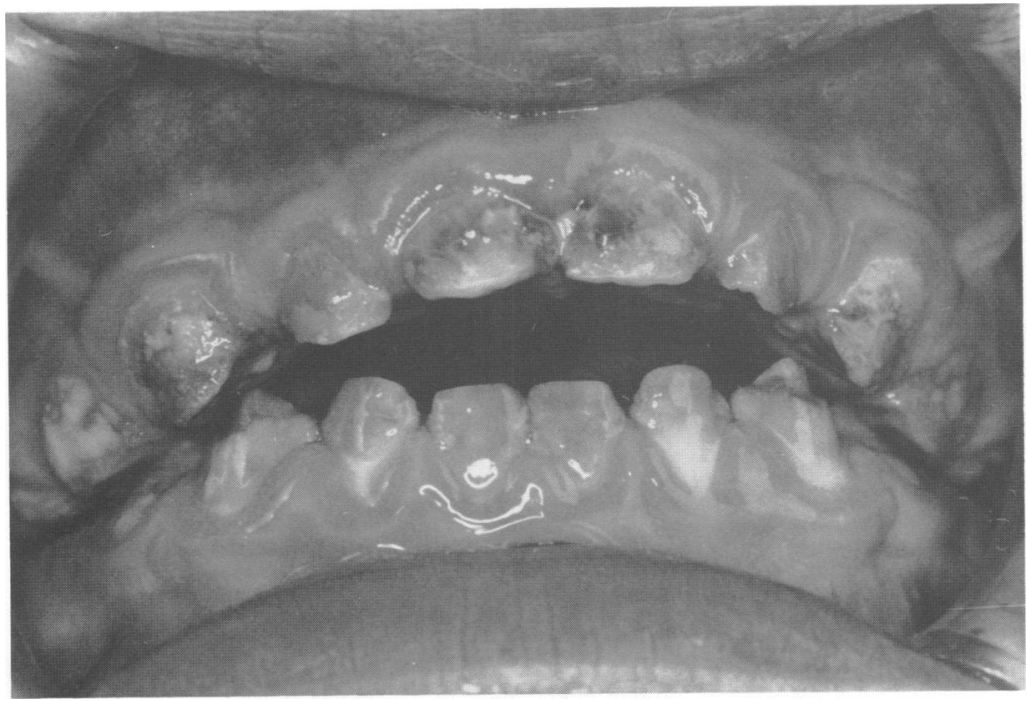

FIG 3 Appearance of dentition of IV.6 at five years of age.

sphingomyelinase, and $\beta$-galactocerebrosidase). A conjunctival biopsy showed no inclusion bodies.

There were five other affected sibs in this family and their clinical details are summarised in the table. They all had normal basic biochemistry and urine metabolic screens. In addition, IV.3 was investigated in more detail. These tests included cultured fibroblast assay of a number of enzymes (pyruvate dehydrogenase, cytochrome c oxidase, succinatecytochrome c reductase, NADH-cytochrome c reductase, and $E_{1}$ ATPase), $G$ banded karyotype, serum uric acid, blood porphyrin screen, blood ammonia, and CSF lactate, pyruvate, and amino acids. All of these gave normal results. None of these children has had CT or MRI brain scans. The mother's plasma phenylalanine was normal.

It was the dental examination of IV.6 which led to the diagnosis of the syndrome in this family. The primary dentition was symmetrically affected by amelogenesis imperfecta of the hypoplastic rough type. The teeth had a yellow colour owing partly to the dentine showing through the abnormally thin enamel and partly to altered enamel structure. Fig 2 shows dental radiographs of IV.6 taken at four years of age and fig 3 shows the appearance of this girl's dentition at the age of five.

\section{Discussion}

The clinical features of the affected members of this kindred fit very closely with the family described by Kohlschütter et al. ${ }^{1}$ In our family, those affected developed normally until the onset of seizures between the ages of seven and 22 months. Psychomotor development slowed with subsequent regression leading to profound intellectual handicap in later childhood in the three oldest affected children. There was difficulty in seizure control.

All affected children showed the same developmental enamel defect known as amelogenesis imperfecta, while the one normal child and the parents have no dental abnormalities. Three of the six affected children have died. Apart from the dental defect no dysmorphic features were observed in the affected members of this family.

The mentally retarded female ancestors noted in the pedigree live in Italy and information about them is not available.

Biochemical and cytogenetic investigations on several affected subjects have failed to show an underlying metabolic defect. We have been unable to explain the raised CSF lactate level in the oldest boy in terms of any metabolic disorder.

Analysis of previous pedigrees has not provided a clear cut single mode of inheritance. This kindred strongly supports autosomal recessive inheritance. Both male and female offspring were affected with equal severity while the parents were clinically normal. The parents have chosen to continue having children despite the risks outlined to them. They are hoping for a normal son.

The most striking physical characteristic in this disorder is amelogenesis imperfecta which was the feature which enabled the syndrome to be diagnosed. Normal development of enamel involves the formation and secretion of an organic matrix con- 
taining the proteins amelogenin and enamelin, starting at seven weeks' gestation for the primary dentition. This is followed by mineralisation of the matrix at nine weeks and subsequent maturation of this enamel with change in enamel protein from predominantly amelogenin to enamelin. ${ }^{2}$ The hereditary defect of enamel, known as amelogenesis imperfecta, occurs as a result of disturbance beginning at the organic matrix stage and continuing through calcification. This occurs with a prevalence of between 1 in 4000 and 1 in $14000 .{ }^{34}$ Amelogenesis imperfecta occurring alone has been described with both autosomal and $\mathrm{X}$ linked inheritance patterns and there are both recessive and dominant forms within each group. ${ }^{4}$ This type of enamel defect, affecting all teeth of both sets of dentition but not developmentally time related, as seen in enamel hypoplastic defects, can occur as mentioned as an isolated defect but does not occur in any other syndrome apart from Kohlschütter's syndrome.

Kohlschütter et $a l^{1}$ postulated a defective gene coding for a single protein related to membrane excitability, enamel formation, and possibly sweat production. Amelogenesis imperfecta is thought possibly to be the result of an alteration in enamelin. ${ }^{5}$ The primordial tissues which give rise to enamel are ectodermal in origin, as is the brain. ${ }^{6}$ Many conditions which exhibit neurological defects also have dental abnormalities as an attendant finding. ${ }^{7}$ It is tempting to hypothesise that the abnormalities in this disorder are related to a defect in ectodermal tissue maturation.

At present treatment remains supportive and it would seem appropriate that any child with amelogenesis imperfecta (generalised tooth enamel defect) should be carefully assessed for the possibility of a neurological disorder.

\section{References}

' Kohlschütter A, Chappuis D, Meter C, Tönz O, Vassella F, Herschkowitz N. Familial epilepsy and yellow teeth-a disease of the central nervous system associated with enamel hypoplasia. Helv Paediatr Acta 1974;29:283-94.

2 Witkop CJ Jr, Sauk JJ Jr. Heritable defects of enamel. In: Stewart RE, Prescott GH, eds. Oral facial genetics. St Louis: Mosby, 1976:151-226.

${ }^{3}$ Wright JT. Analysis of a kindred with amelogenesis imperfecta. $J$ Oral Pathol 1983;14:366-74.

${ }^{4}$ Sundel S, Koch G. Hereditary amelogenesis imperfecta. 1. N Epidemiology and clinical classification in a Swedish child population. Swed Dent J 1983;9:157-69.

5 Menanteau J, Mitre D, Raher S. An in vitro study of enamel protein degradation in developing bovine enamel. Arch Oral Biol 1986;12:807-10.

${ }^{6}$ Moore KL. The skin, cutaneous appendages and teeth. In: The developing human. Philadelphia: Saunders, 1982:228-31.

${ }^{7}$ Smith DW. Appendix. Pattern of malformation differential diagnosis by anomalies. In: Recognizable patterns of human malformations. Philadelphia: Saunders, 1982:27-8.

Correspondence and requests for reprints to $D$ John Christodoulou, Department of Geneticso Royal Children's Hospital, Flemington Road, Park:ville, Victoria 3052, Australia. 